\title{
Communication \& Language Codes in Evaluating HuMAN RESOURCES IN VIRTUAL ENTERPRISES
}

\author{
NicA, G. B.; Aurite, T.; Dumitrescu, D. M. \& Popescu, B. M.
}

Abstract: For the human resources acting in virtual enterprises environment is important to be able to develop specific skills in communication. Only a good management of language codes and communication behavior allows SME's teams to imply themselves in international projects, where they can cover using their skills specific tasks, modules of the project proposed by the big enterprises who are leading the field. We present in this paper our proposal to modify the specific relevant psychological CPI profiles match to psychological scales of MBTI, for the mechanical engineers as defined in our previous researches, in order to also evaluate their ability to communicate in the Virtual Enterprise (VE) environment.

Key words: language codes, communication behavior, CP and MBTI test, virtual enterprise environment
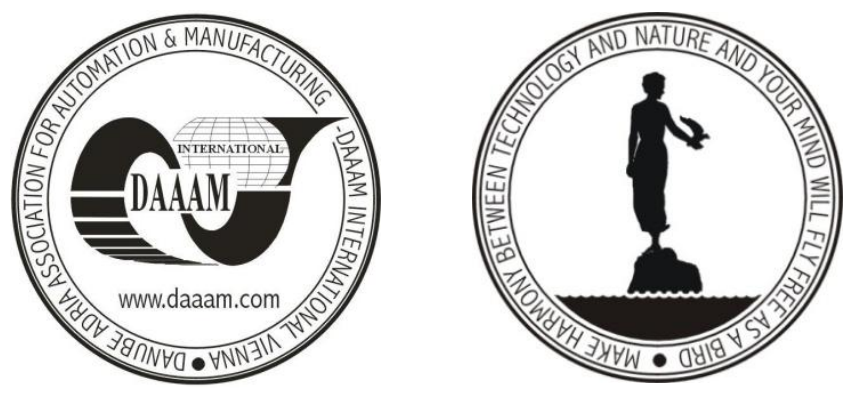

Authors' data: $\mathrm{PhD}$. Student Nica, G[abriela] B[eatrice]*; Univ. Prof Dr. eng. Aurite, T[raian]*; PhD. Student Dumitrescu D[iana] M[ariana]**; Dr. Popescu B[ogdan] M[ihai]*, *University Politechnica of Bucharest, Spl. 313, 060042, Bucharest, Romania, **National School of Political and Administrative Studies, Faculty of Political Sciences, Str Povernei 6, Bucharest, Romania, beatrice@mix.mmi.pub.ro, aurite@amcsit.ro, diana.dumitrescu84@yahoo.com, bm_popescu@yahoo.com

This Publication has to be referred as: Nica, G[abiela] B[eatrice]; Aurite, T[raian]; Dumitrescu D[iana] M[ariana] \& Popescu B[ogdan] M[ihai] (2010). Communication \& Language Codes in Evaluating Human Resources in Virtual Enterprises, Chapter 58 in DAAAM International Scientific Book 2010, pp. 669-678, B. Katalinic (Ed.), Published by DAAAM International, ISBN 978-3-901509-74-2, ISSN 1726-9687, Vienna, Austria

DOI: $10.2507 /$ daaam.scibook.2010.58 


\section{Introduction}

The multinational culture has an impact over all the aspects of economic, social and even political life of many countries. The organizational culture of multinational enterprises has a declared role in influencing, the professional traditions and experience, by cultivating higher and more efficient standards and values. However, even if developing the social standards of some industrial countries, multinational organizational cultures may be responsible for inducing dependence, inadequate practices, and hard to assimilate industrial values to the host country. The multinational culture provides liaison between the local know how \& resources and the communication technology. What we learned in both settings, regional and global networks, is that managerial competence to rapidly change the cooperative organizational arrangement from within must be backed by the cooperative culture of the partners (Katzy, 1998).

The concept of multinational enterprise culture is more and more corroborated in last years with virtual enterprises environment.

A virtual enterprise (VE) architecture represents a temporary consortium of independent member companies which come together to quickly exploit fastchanging worldwide product manufacturing opportunities during a project lifetime (figure 1).

Different organizational cultures (ethnocentric, polycentric, regiocentric, geocentric) were proposed for this kind of enterprise architecture. At the moment the geocentric organizational culture (figure 2) seems to be the best choice because of his high degree of international coordination on production, with an important degree of independence observable across branch companies, and an important orientation towards satisfying the demand among local markets

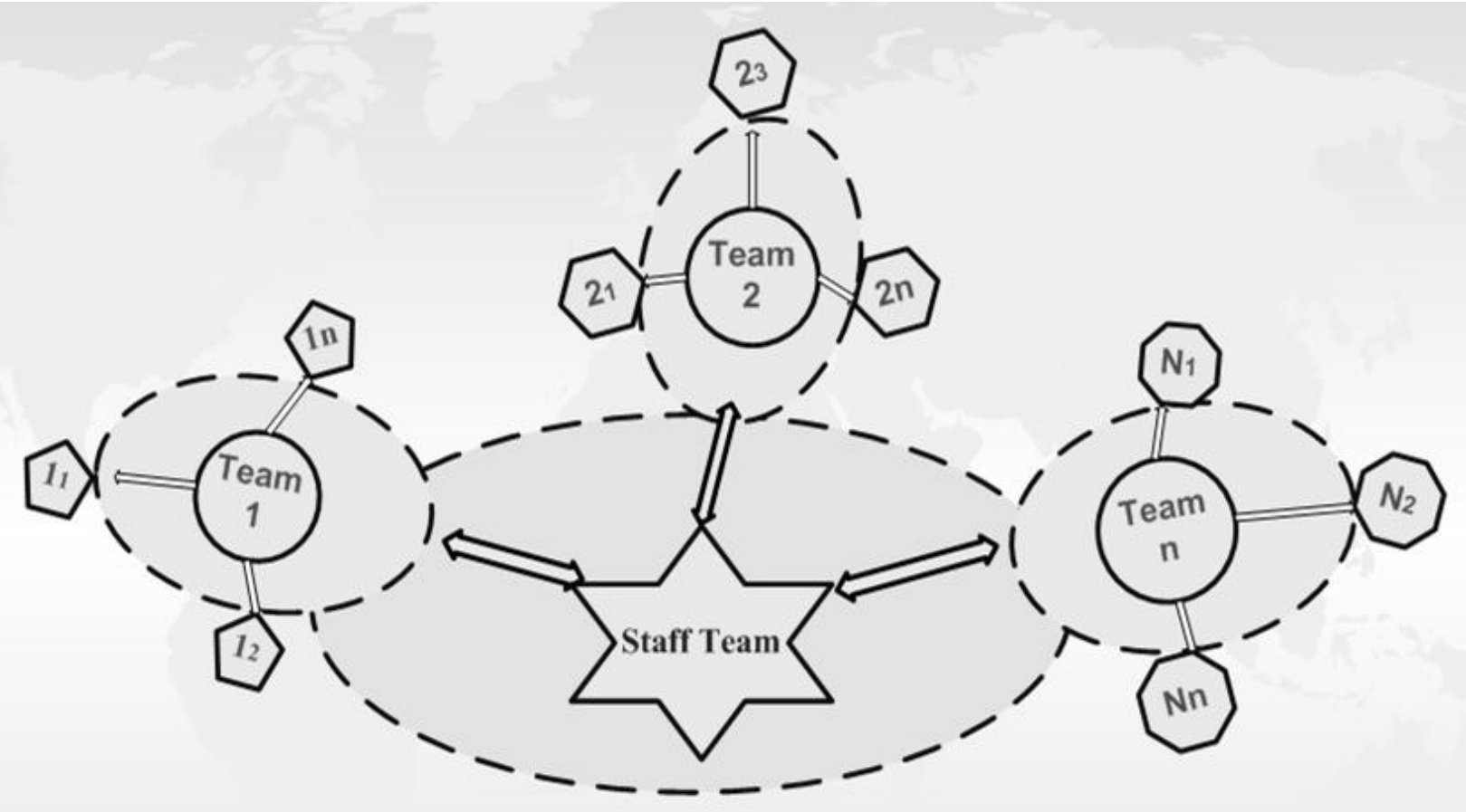

Fig. 1. Communication in VE 


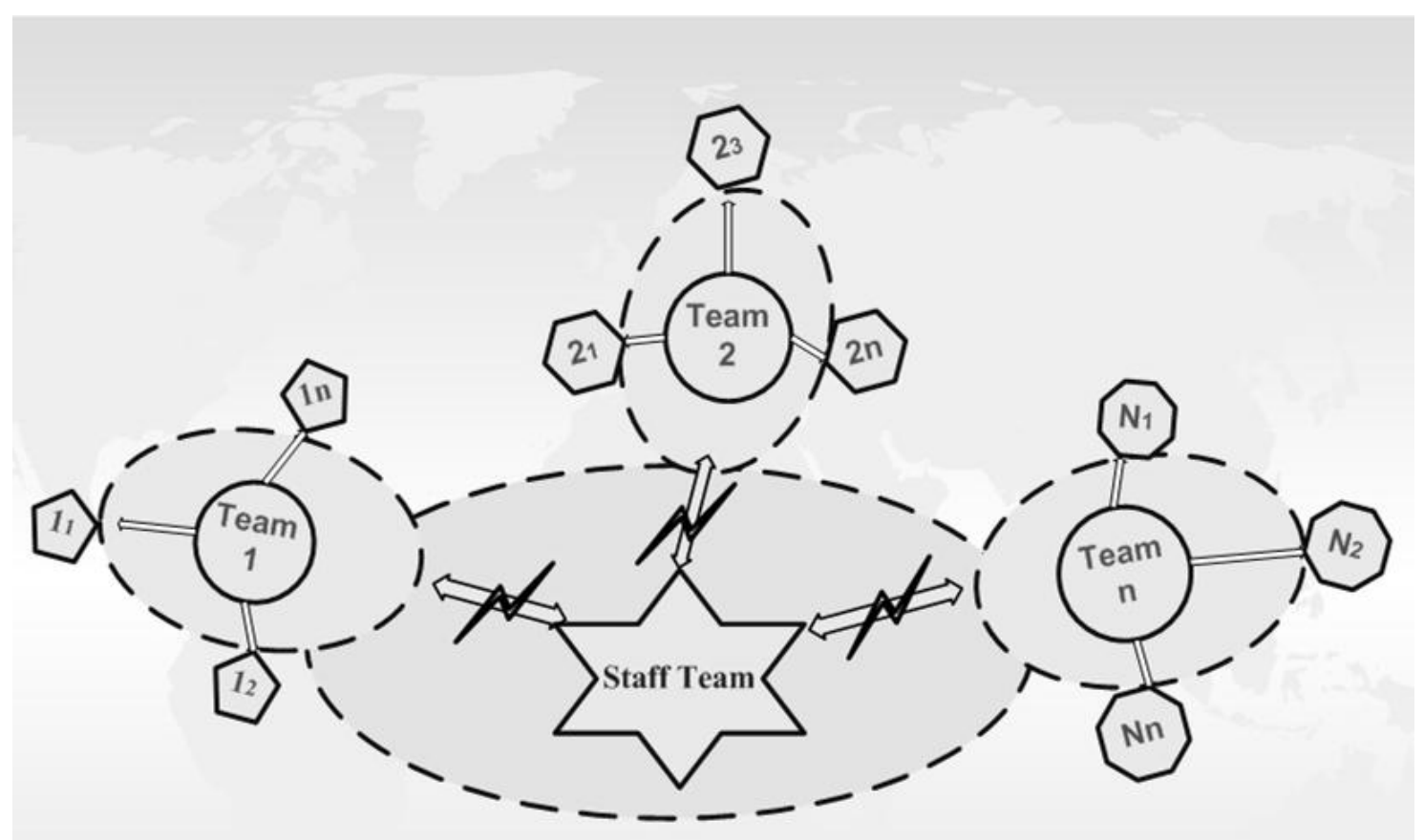

Fig. 2. Breaking the waves of communication in VE

In this kind of organizational culture the heads of the branch companies enjoy greater autonomy and decision-taking is more horizontal, tending to be carried out among branch managers. Local communication management process is emphasized at the level of each team in every node of the VE network as well as the increased need for communication management of the entire VE architecture. One of the main issues in communication management for such virtual team architecture is located in language codes and communication behaviour. If those problems are neglected the organizational communication codes between partners may induce very severe differences between the reality images at the level of the emitter and receptor.

\section{Breaking the waves}

Effective communication is fundamental to all aspects of human functioning.

We can define the communication as transfer of the information waves from a sender to a receiver under the requirements that the message have been perceived with the same signification of the content by two subjects. Efficiency in communication is conditioned by the understanding of the message (figure 3 ).

Social/communications skills predict vocational functioning history independently of cognitive performance, and social skills Deficits in social/communications skills have been documented in schizophrenia, but it is unclear how these deficits relate to cognitive deficits and to everyday functioning.

Communication is best achieved through simple planning and control (Blair, 1993).

To ensure an efficient and effective conversation, there are three considerations:

- you must make your message understood

- you must receive/understand the intended message sent to you 


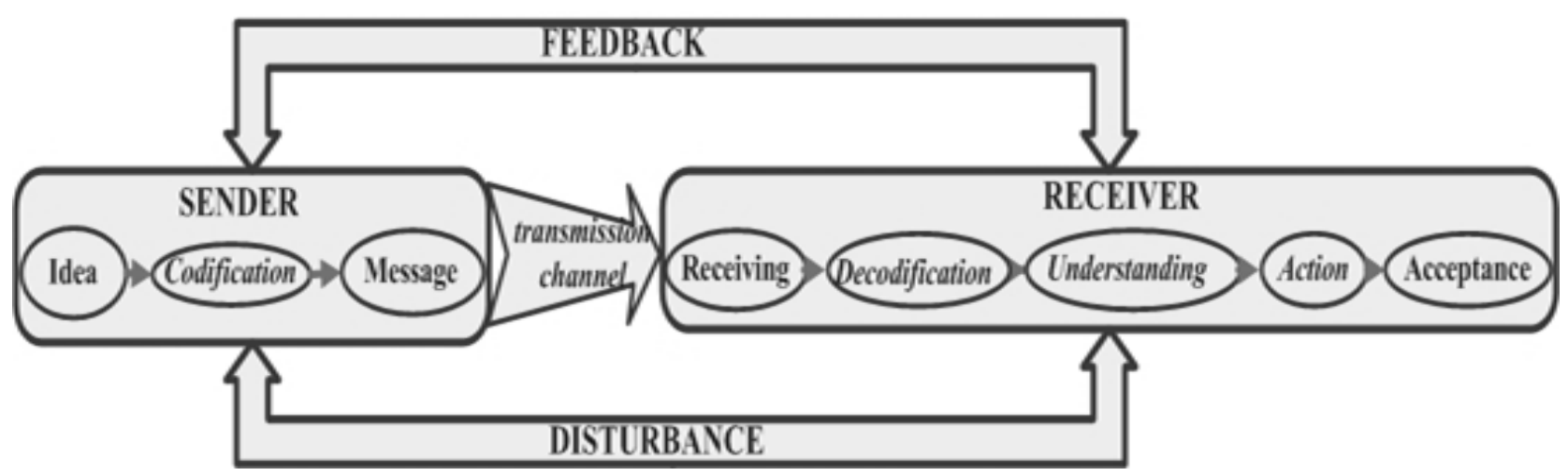

Fig. 3. Communication

- you should exert some control over the flow of the communication

It is important to view that words should be rather pragmatic than philosophical. Thus, words mean not what the dictionary says they do but rather what the speaker intended.

Thus we must learn to listen as well as to speak. Those who dismiss this as mere platitudes are already demonstrating an indisposition to listening: the phrase may be trite, but the message is hugely significant to your effectiveness as a manager. If you do not explicitly develop the skill of listening, you may not hear the suggestion/information which should launch you to fame and fortune.

A problem is that some people simply make mistakes. Your job is not simply to spot ambiguities but also to counter inconsistencies. Thus if I now advocate that the wise manager should seek out (perhaps humorous) books on entomology (creepy crawlies) you would deduce that the word should have been etymology. More usual, however, is that in thinking over several alternatives you may suffer a momentary confusion and say one of them while meaning another. There are good scientific reasons (to do with the associative nature of the brain) why this happens, you have to be aware of the potential problem and counter for it.

As with all effective communication, you should decide (in advance) on the purpose of the conversation and the plan for achieving it. There is no alternative to this. Some people are proficient at "thinking on their feet" - but this is generally because they already have clear understanding of the context and their own goals. You have to plan; however, the following are a few techniques to help the conversation along.

Avoid a breaking the wave information's, the communication must be:

- Assertiveness - The definition of to assert is: "to declare; state clearly". This is your aim. If someone argues against you, even loses their temper, you should be quietly assertive.

- Confrontations - When you have a difficult encounter, be professional; do not lose your self-control because, simply, it is of no use. Some managers believe that it is useful for "discipline" to keep staff a little nervous.

- Seeking Information - There are two ways of phrasing any question: one way (the closed question) is likely to lead to a simple grunt in reply (yes, no, maybe), the 
second way (the open question) will hand over the speaking role to someone else and force them to say something a little more informative.

More usual, however, is that in thinking over several alternatives you may suffer a momentary confusion and say one of them while meaning another. There are good scientific reasons (to do with the associative nature of the brain) why this happens, you have to be aware of the potential problem and counter for it.

The problem is to choose from the word multiple meanings the one intended. Especially when the waves of communication are made via Internet, the real meaning might be obstructed by the poor communication codes. Basic luck of trust due to the only virtual contact of the sender \& receiver is breaking the communication waves.

\section{Adapting psychological tests}

In the heretofore research, we have tried to define the psychological profile which must be in keeping with the specifically profile demanded by the virtual construct and we chosen California Psychological Inventory (CPI).

After the successively application on the group (62 students) we have discovered that the profile anterior defined is not adequate with the requirements which are implied by the virtual communication environment. Hereupon, in the evaluation and analysis of the psychological profile, we made a point of a MyersBriggs Type Indicator (MBTI) to be introduced.

Psychometric and conceptual analyses of the CPI instrument have identified three basic dimensions underlying scores on the folk and special purpose scales. The items on the inventory produce scores for 18 scales, which are divided into four classes: measures of poise, ascendancy, self-assurance and inter-personal adequacy; measures of socialization, responsibility, intra-personal values, and character; measures of achievement potential and intellectual efficiency; and measures of intellectual and interest modes. The underlying logic here is interpretational, not factorial, i.e., these four categories do not necessarily constitute psychometric entities." Psychometric and conceptual analyses of the CPI instrument have identified four basic dimensions underlying scores on the folk and special purpose scales (Gough et al., 1996).

Two of these themes are manifestations of fundamental orientations - toward people and toward societal values. The third is an indicator of ego integration or competence as seen by others, or self-realization as seen by the respondent.

The first sector of the profile - DEALING WITH OTHERS - contains scales assessing interpersonal style and manner of dealing with others. From an analysis of the six scales in this region of the profile we can get an impression of how he approaches others, and of qualities such as self-confidence, poise, and initiative. The first scale assesses a continuum going from a participative, involved, and extroversive orientation at the low end, to a detached, internal, and introversive orientation at the high pole.

The next sector of the profile - SELF-MANAGEMENT contains scales pertaining to the internalization and endorsement of normative conventions, including norms related to self presentation. From an analysis of scores in this region, we can obtain an impression of how he views social norms and how his conduct is affected 
Nica, G.B.; Aurite, T.; Dumitrescu, D.M. \& Popescu, B.M.: Communication \& ...

by these considerations. The second scale assesses a continuum going from a norm questioning, rule - doubting orientation at one extreme, to a norm-accepting, rulefavoring orientation at the other. Each type or lifestyle has its own specific modes of self-actualization and its own specific modes of psychopathology.

The third sector of the profile - MOTIVATIONS AND THINKING STYLE sheet contains three scales pertaining to cognitive/intellectual functioning and the need for achievement in either structured or open situations. From an analysis of scores in this region we can obtain an impression of how he behaves with respect to these matters. Level of ego integration or self-realization is indicated by scores on the third scale.

The final sector of the profile - PERSONAL CHARACTERISTICS - sheet contains three scales that assess broadly stylistic or qualitative aspects of thinking and behavior. The scores on these scales have implications in their own right, but also serve to color or even modify the expectations attached to higher or lower scores on the preceding scales. The type and level classifications given just above furnish initial guidance for interpreting this protocol. This analysis of each of the 18 scales will lead to more specific comments than can be derived from type and level alone. A professional, individuated interpretation can, of course, go farther than this, taking account of patterns and configurations among the scales. A decision about whether or not an individual's results on an instrument are valid enough for interpretation is a professional judgment (Research Department CPP, 2005).

From the 18 scales of CPI, 10 were selected (Do, Sp, Sa - Class I; Re, So Class II; Ai, Ie - Class III and Fx - Class IV) as the most relevant to the specific requirements for a good communications (Table 1).

\begin{tabular}{|c|c|}
\hline $\begin{array}{l}\text { CLASS I } \\
\text { DEALING WITH OTHERS }\end{array}$ & $\begin{array}{l}\text { CLASS II } \\
\text { SELF-MANAGEMENT }\end{array}$ \\
\hline $\begin{array}{l}\text { Do - assertive, forceful, self-confident } \\
\text { initiative and gets things done } \\
\text { charismatic leader }\end{array}$ & $\begin{array}{c}\text { Re - conscientiously, reliable person with } \\
\text { a strongly developed inner sense of } \\
\text { ethics and personal integrity }\end{array}$ \\
\hline $\begin{array}{l}\text { Sp - is spontaneous, and clever verbally } \\
\text { fluent }\end{array}$ & \multirow{2}{*}{$\begin{array}{l}\text { So - reliable, dependable, conscientious, } \\
\text { works well with others }\end{array}$} \\
\hline $\begin{array}{l}\text { Sa - good at avoiding interpersonal } \\
\text { friction and conflict is usually liked } \\
\text { and accepted by others }\end{array}$ & \\
\hline $\begin{array}{l}\text { CLASS III } \\
\text { MOTIVATIONS AND THINKING } \\
\text { STYLE }\end{array}$ & $\begin{array}{l}\text { CLASS IV } \\
\text { PERSONAL CHARACTERISTICS }\end{array}$ \\
\hline $\begin{array}{l}\mathbf{A i} \text { - will show excellent achievement } \\
\text { intelligent, clear-thinking, and } \\
\text { imaginative }\end{array}$ & \multirow[t]{2}{*}{$\begin{array}{l}\text { Fx - adapts well to change and to new } \\
\text { conditions, clever and spontaneous }\end{array}$} \\
\hline $\begin{array}{c}\text { Ie - intelligent, clear-thinking person, } \\
\text { verbally fluent, feels sure of self, } \\
\text { equal to nearly any challenge }\end{array}$ & \\
\hline
\end{tabular}

Tab. 1. Psychological scales of CPI selected 
The Myers-Briggs (MBTI) personality test is based on Carl Jung's theory of Personality Types (Hirsh et al., 2003). This theory suggests that there are two different ways of gaining energy, gathering or becoming aware of information, making decisions and dealing with the outside world.

This instrument for measuring a person's preferences is using four basic scales with opposite poles.

Whether we are introverts or extroverts, we need to deal with the world, inner and outer. And each of us has our preferred ways of dealing with it, ways we are comfortable with and good at. Jung suggests there are four basic ways, or functions:

The first is sensing. Sensing means what it says: getting information by means of the senses. A sensing person is good at looking and listening and generally getting to know the world. Jung called this one of the irrational functions, meaning that it involved perception rather than judging of information.

The second is thinking. Thinking means evaluating information or ideas rationally, logically.

Jung called this a rational function, meaning that it involves decision making or judging, rather than simple intake of information.

The third is intuiting. Intuiting is a kind of perception that works outside of the usual conscious processes. It is irrational or perceptual, like sensing, but comes from the complex integration of large amounts of information, rather than simple seeing or hearing. Jung said it was like seeing around corners.

The fourth is feeling. Feeling, like thinking, is a matter of evaluating information, this time by weighing one's overall, emotional response. Jung calls it rational, obviously not in the usual sense of the word.

We all have these functions. We just have them in different proportions, you might say. Each of us has a superior function, which we prefer and which is best developed in us, a secondary function, which we are aware of and use in support of our superior function, a tertiary function, which is only slightly less developed but not terribly conscious, and an inferior function, which is poorly developed and so unconscious that we might deny its existence in ourselves.

Some of the most important recent work done in the field on Personality Typing has been done by David Keirsey, who has created the theory of temperament associated with type. In his research, he has made observations that have allowed him to combine two of the four sets of preferences, into four distinct temperament categories.

Each of the sixteen personality types fits into one of these temperament categories. The titles used here for the temperament types, and the individual personality types listed within each temperament, are Kersey's own descriptions. You'll notice that they do not match our labels for the types (Keirsey, 1984).

The MBTI (Myers-Briggs Type Indicator), one of the most well used personality indicators used in the psychological fields today, is designed to help to understand the unique personality and the way you relate to others around you.

The four scales are: extraversion/introversion, sensate/intuitive, thinking/feeling, and judging/perceiving. 
Nica, G.B.; Aurite, T.; Dumitrescu, D.M. \& Popescu, B.M.: Communication \& ...

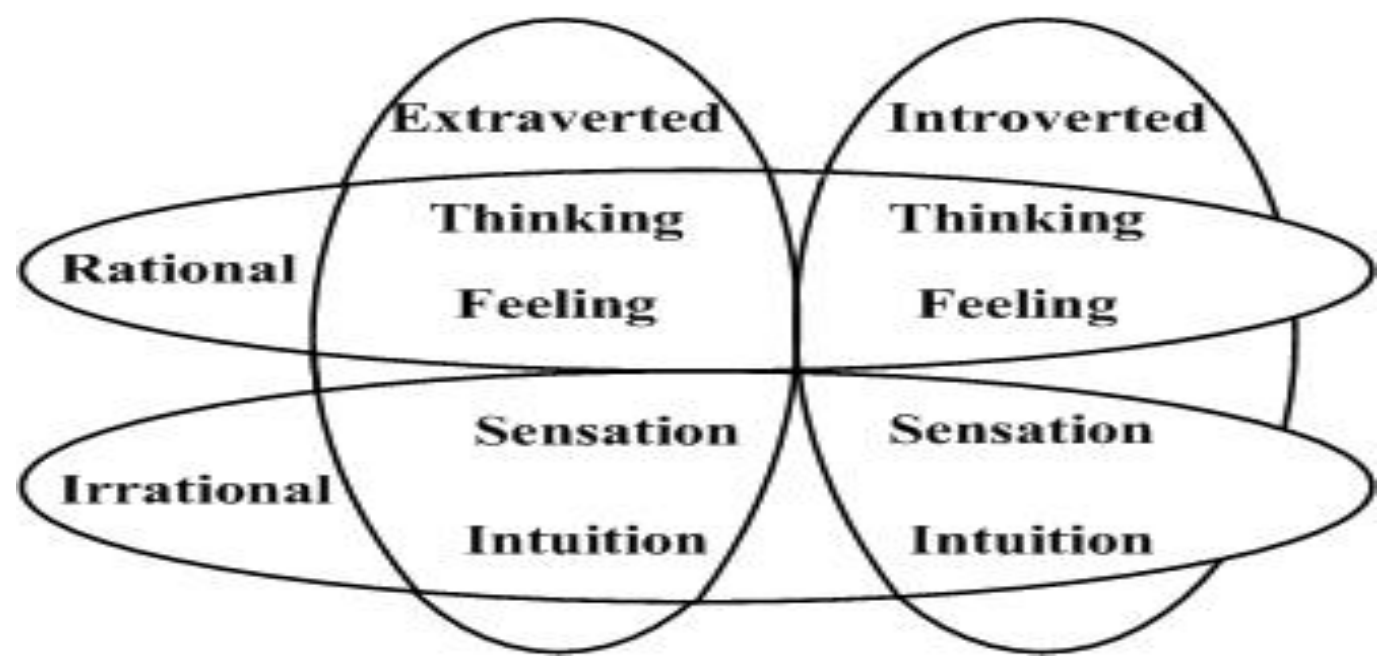

Fig. 4. Myers-Briggs Type Indicator

The various combinations of these preferences result in 16 personality types which own the rights to the instrument. Types are typically denoted by four letters for example, INTJ (Introversion, Intuition with Thinking and Judging)-to represent one's tendencies on the four scales (figure 4).

MBTI is a tool that can be used to achieve effective communication with other people. People receive, process, and act upon information differently. If you understand their preferences and then communicate in a way that they understand, chances are you will not only get what you expected, but those with whom you communicate will feel good about how they received and acted on your communication (Table 2). Starting point from request of an efficiency communication in a virtual enterprise, we selected the following scales:

\section{Gaining Energy}

Extraversion (E)- Focused on the Introversion (I)- Focused on the inner outside world and get energy through world and get energy through reflecting interacting with people and doing on information, ideas and/or concepts. things.

\section{Gathering Information}

Sensing (S) - Notice and trust facts, details, and present realities.
Intuition (N) - Attend to and trust interrelationships, theories and future possibilities.

\section{Making Decisions}

Thinking (T) - Make decisions using Feeling (F) - Make decisions to create logical, objective analysis harmony by applying person-centered values.

\section{Dealing with the World}

Judging (J) - Organized, orderly and Perceiving (P) - Flexible, adaptable and decisive like to keep options open.

Tab. 2. MBTI scales 
- ESTJ - the persons ESTJ takes his/her energy from the outside world of actions and spoken words.

$\mathrm{He} / \mathrm{she}$ prefers dealing with facts and the present, and makes decisions using logic. His/her life is organized on a logical basis. He/she is therefore practical, and likely to implement tried and trusted solutions to practical problems in a businesslike and impersonal manner. He/she prefers to ensure that the details have been taken care of rather than spend time considering concepts and strategies.

- ESFP - the persons ESFP takes his/her energy from the outside world of actions and spoken words.

$\mathrm{He} / \mathrm{she}$ prefers dealing with facts, which he/she usually takes at face value. He/she also prefers dealing with the present and with people, and probably derives much enjoyment out of friendships. His/her life is flexible, living it very much in the present, and responding to things as they arise. He/she is impulsive and friendly, seeking enjoyment out of life, and makes new friends easily.

$\mathrm{He} / \mathrm{she}$ likes taking part in solving urgent problems, such as fire-fighting or trouble shooting. He/she operates best in practical situations involving people.

- ESFJ - the persons ESFJ takes his/her energy from the outer world of actions and spoken words.

$\mathrm{He} / \mathrm{she}$ prefers dealing with facts, and making decisions on the basis of personal values. He/she likes dealing with people, and organizes life on a personal basis. $\mathrm{He} / \mathrm{she}$ is a very warm person, seeking to maintain harmonious relationships with colleagues and friends, who are a very important part of his/her life. He/she can find conflict and criticism very difficult to handle. He/she has a strong sense of duty and loyalty, and is driven by a need to belong and be of service to people.

- ESTP - the persons ESTP takes his/her energy from the outer world of actions and spoken words.

$\mathrm{He} / \mathrm{she}$ prefers dealing with facts, which he/she usually views objectively, and he/she makes decisions on a logical basis. His/her life is flexible, consisting of a series of activities that interest his/her. He/she is an action oriented problem solver, and prefers to work with practical organizational issues. He/she can be impulsive, and likes taking part in trouble-shooting-type work. He/she can sometimes neglect follow-through, but will work best when there is a lot going on that needs organizing and solving.

- ENFJ - the persons ENFJ takes his/her energy from the outer world of actions and spoken words.

$\mathrm{He} / \mathrm{she}$ prefers dealing with patterns and possibilities, particularly for people, and makes decisions using personal values. His/her life is organized on a personal basis, seeking to develop and maintain stable relationships with those people he/she likes. He/she is actively concerned with promoting personal growth in others.

$\mathrm{He} / \mathrm{she}$ is also highly sociable, and expressive of feelings towards others, but can find conflict and criticism difficult, particularly if it might damage long term relationships. He/she works best in situations involving people.

- ENTP - the persons ENTP takes his/her energy from the outer world of actions and spoken words. 
$\mathrm{He} / \mathrm{she}$ prefers dealing with patterns and possibilities, and making decisions on a logical basis. He/she is adaptable, tending to focus on new ideas and interests as and when they arise, particularly if they involve increasing his/her competence or skill. $\mathrm{He} / \mathrm{she}$ is an ingenious problem solver, constantly trying new ideas out, and can seem to enjoy a good argument. He/she is interested in instigating change, and operates best in overcoming new difficulties where the solution requires the application of creative effort.

\section{Conclusion}

Virtual teams can be described as teams with virtual communication links and groupware products (Gould, 1999). We observed that a person's MBTI preference could be the key to becoming a good communicator. We have to understand how people receive, perceive, and understand what someone asks them to do. If we understand what motivates them, we can communicate the necessity of the task in a manner that they perceive and receive it as important, and the task will be as important to them as to the sender.

That is the reason why we adapted our CPI based test used in human resources evaluation in order to include those new profiles adapted from MBTI. Using those personalized test one can quantify the communication skills of human resources working in VE environment.

Our future research will focus on the posibilities to combine and differentiate the importance of profiles from different inventories quantifying the compatibility between the obtained psychological profile for the evaluated person and the necessary one according to the technical capacities required.

\section{References}

Blair, G. M. (1993). Starting to Manage: The Essential Skills, Publisher: Chartwell Bratt Ltd, ISBN-10: 0862383366

Dunning, J. H. (1993) Multinational Enterprise and the World Economy, AddisonWesley Publishing Company

Gough, H. G. \& Bradley, P. (1996). The California Psychological Inventory ${ }^{\mathrm{TM}}$ manual - Third edition (2002 Printing). Palo Alto, CA: CPP, Inc.

Gould, D. (1999). "Virtual Teams", Available from: http://www.seanet.com/[sim]daveg/vrteams.htm, Accessed on: 2006-07-19

Hirsh, E.; Hirsh, K. W. \& Hirsh, S. K. (2003). Introduction to Type ${ }^{\circledR}$ and teams (2nd ed.). Palo Alto, CA: CPP, Inc.

Katzy, B. R. (1998). Virtual Enterprise and Europe's Global Competitiveness, in: Proceedings of the Competing in the Information Society, Genoa, CEC

Keirsey, D. (1984). Please Understand Me: Character and Temperament Type, 1st Ed., Prometheus Nemesis Book Co. ISBN 1885705026.

Research Department CPP (2005), Inc., Brief Technical Report on the CPI 260 Instrument Available from http:// www.cpp.com/articles/pdf, Accessed on: 2005-04-19 